\title{
ẢNH HƯởNG CỦA KHẢ NĂNG THANH KHOẢN CỔ PHIẾU ĐẾN CHÍNH SÁCH CHI TRẢ CỔ TỨC: BẰNG CHỨNG THỰC NGHIỆM TƯ CÁC DOANH NGHIÊPP NIÊM YẾT TRÊN SỞ GIAO DỊCH CHÚNG KHOÁN TP. HỒ CHÍ MINH (HOSE)
}

\author{
Phùng Đức Namª ${ }^{\mathrm{a}}$ Hoàng Thị Phương Anha ${ }^{\mathrm{a}^{*}}$, Lê Thị Thanh Vươnga \\ ${ }^{a}$ Khoa Tài chính, Truòng Đại học Kinh tế TP. Hồ Chí Minh, TP. Hồ Chí Minh, Việt Nam \\ "Tác giả liên hệ: Email: anhtcdn@ueh.edu.vn \\ Lịch sử bài báo \\ Nhận ngày 23 tháng 04 năm 2018 \\ Chỉnh sửa ngày 03 tháng 06 năm 2018 | Chấp nhận đăng ngày 04 tháng 06 năm 2018
}

\section{Tóm tắt}

Mục tiêu của bài nghiên cúu này là nhằm kiểm định mối quan hệ giũa tính thanh khoản của cổ phiếu và chính sách chi trả cổ tức của 267 doanh nghiệp (DN) được niêm yết trên Sở Giao dịch chúng khoán TP. Hồ Chí Minh (HOSE) trong giai đoạn tù năm 2008-2016. Kết quả cho thấy mối quan hệ ngược chiều và có ý nghĩa thống kê của hai yếu tố này ở thị trương Việt Nam. Điều này có nghĩa là khi cổ phiếu của một doanh nghiệp có tính thanh khoản càng cao thì xác suất để doanh nghiệp đó không chi trả cổ tức hoặc chi trả cổ tức tiền mặt sẽ thấp.

Từ khóa: Chính sách chi trả cổ tức; HOSE; Thanh khoản cổ phiếu.

Mã số định danh bài báo: http://tckh.dlu.edu.vn/index.php/tckhdhdl/article/view/461

Loại bài báo: Bài báo nghiên cứu gốc có bình duyệt

Bản quyền @ 2018 (Các) Tác giả.

Cấp phép: Bài báo này được cấp phép theo CC BY-NC-ND 4.0 


\title{
THE IMPACTS OF STOCK LIQUIDITY ON DIVIDEND POLICY: EVIDENCE FROM LISTED FIRMS ON HOCHIMINH STOCK EXCHANGE
}

\author{
Phung Duc Nama ${ }^{\mathrm{a}}$ Hoang Thi Phuong Anh ${ }^{\mathrm{a}^{*} \text {, Le Thi Thanh Vuonga }}$ \\ ${ }^{a}$ School of Finance, University of Economics Hochiminh City, Hochiminh City, Vietnam \\ ${ }^{*}$ Corresponding author: Email: anhtcdn@ueh.edu.vn
}

Article history

Received: April 23 ${ }^{\text {rd }}, 2018$

Received in revised form: June $03^{\text {rd }}, 2018 \mid$ Accepted: June $04^{\text {th }}, 2018$

\begin{abstract}
This study investigates the relationship between stock liquidity and corporate dividend policy of 267 listed firms on Hochiminh Stock Exchange during the period from 2008 to 2016. The empirical results statistically indicate a significant negative relationship between stock liquidity and dividend policy in the context of Vietnam. This means that when a company has a stock with high liquidity, there will be a high possibility that the company will not pay out dividends or pay no dividends.
\end{abstract}

Keywords: Dividend policy; HOSE; Stock liquidity.

Article identifier: http://tckh.dlu.edu.vn/index.php/tckhdhdl/article/view/461

Article type: (peer-reviewed) Full-length research article

Copyright (C) 2018 The author(s).

Licensing: This article is licensed under a CC BY-NC-ND 4.0 


\section{GIỚI THIỆ}

Cùng với quyết định nên lựa chọn cơ hội đầu tư nào và sử dụng nguồn tài trợ ra sao để thực hiện các cơ hội đầu tư đó, thì quyết định chi trả cổ tức cũng là một quyết định tài chính quan trọng trong một DN. Vì là một quyết định quan trọng nên hầu hết các nhà quản trị luôn muốn tìm hiểu xem những yếu tố nào có thể ảnh hưởng đến quyết định lựa chọn chính sách chi trả cổ tức để đem lại giá trị tối đa cho DN. Mặc dù trước đây đã có nhiều nghiên cứu thực nghiệm nói về chính sách chi trả cổ tức ở các thị trường khác nhau, tuy nhiên hầu hết các nghiên cứu đều tập trung vào phân tích các yếu tố tác động đến chính sách chi trả cổ tức của công ty, các yếu tố này thường là các yếu tố thể hiện những đặc trưng của $\mathrm{DN}$ như quy mô, khả năng sinh lợi, cấu trúc vốn... Cũng có các nghiên cứu nói về ảnh hưởng của khả năng thanh khoản nhưng chỉ dừng lại ở khả năng nắm giữ tiền mặt của $\mathrm{DN}$, rất ít các nghiên cứu đề cập đến tính thanh khoản của cổ phiếu công ty. Trong những năm gần đây, có một vài nghiên cứu trên thế giới đã đi tìm câu trả lời cho mối quan hệ giữa tính thanh khoản của cổ phiếu và chính sách chi trả cổ tức của DN như nghiên cứu của Banerjee, Gatchev, và Spindt (2007); Brockman, Khurana, và Martin (2008); và Kuo, Philip, và Zhang (2013) cho thấy rằng quyết định chi trả cổ tức bằng tiền mặt và tính thanh khoản của cổ phiếu có quan hệ nghịch chiều nhau. Tức là cổ phiếu của một $\mathrm{DN}$ có tính thanh khoản càng cao thì xác suất công ty không tiến hành chi trả cổ tức càng cao hoặc trả cổ tức tiền mặt thấp và ngược lại. Tuy nhiên, nghiên cứu gần đây nhất của Jiang, $\mathrm{Ma}$, và Shi (2017) lại cho kết quả thể hiện mối quan hệ cùng chiều giữa chính sách chi trả cổ tức và tính thanh khoản của cổ phiếu. Chính vì vậy, mục tiêu chính của nghiên cứu này là đi tìm câu trả lời thực nghiệm về mối quan hệ giữa thanh khoản và chính sách chi trả cổ tức của $\mathrm{DN}$ trên Thị trường chứng khoán Việt Nam, do theo tìm hiểu của chúng tôi ở Việt Nam hiện nay chưa có một nghiên cứu thực nghiệm nào về vấn đề này, nên việc thực hiện nghiên cứu này là cần thiết.

\section{TỔNG QUAN CÁC NGHIÊN CÚUU TRƯớC ĐÂY}

Nghiên cứu của Miller và Modigliani (1961) là một trong những nghiên cứu nổi bật về chính sách cổ tức khi thấy rằng trong điều kiện thị trường hoàn hảo (không có thuế, không có chi phí giao dịch, giá cả không chịu tác động của yếu tố cung cầu, không có bất cân xứng thông tin...) giá trị $\mathrm{DN}$ chỉ phụ thuộc vào các cơ hội đầu tư, chính sách cổ tức hoàn toàn không có tác động đến giá trị $\mathrm{DN}$. Bởi vì trong thị trường này các nhà đầu tư có thể ngay lập tức mua bán chuyển đổi chứng khoán một cách dễ dàng mà không phải gánh chịu bất cứ chi phí giao dịch trực tiếp hay gián tiếp nào và vì vậy không làm thay đổi giá của cổ phiếu. Tuy nhiên vì thị trường luôn tồn tại các bất hoàn hảo nên nghiên cứu của Miler và Modigliani (1961) đã vấp phải nhiều tranh cãi. Nhận thức được bất cập có liên quan đến chi phí giao dịch, Miller và Modigliani (1961) hàm ý rằng, đối với các $\mathrm{DN}$ có tính thanh khoản cổ phiếu thấp (chi phí giao dịch cao) thường có khuynh hướng chi trả cổ tức cao hơn. Như vậy, theo Miller và Modigliani (1961), tính thanh khoản của cổ phiếu có quan hệ nghịch chiều với quyết định chi trả cổ tức. 
Nghiên cứu của Banerjee và ctg. (2007) xem xét mối quan hệ giữa tính thanh khoản của cổ phiếu trên thị trường chứng khoán và chính sách chi trả cổ tức của các công ty trên Thị trường chứng khoán Mỹ. Vấn đề đặt ra có liên quan đến chi phí giao dịch. Trong thị trường không có chi phí giao dịch, các nhà đầu tư có nhu cầu tiền mặt có thể tự tạo cổ tức cho mình bằng cách bán một lượng cổ phần thích hợp đang nắm giữ, kết quả là không có sự khác biệt giữa việc họ nhận được cổ tức tiền mặt và việc bán cổ phần của mình. Còn trên thực tế, trong thị trường vốn có chi phí giao dịch, các cổ phiếu chi trả cổ tức tiền mặt cho phép các nhà đầu tư thỏa mãn nhu cầu tiền mặt của mình mà không cần phải bán cổ phiếu, do đó tránh được chi phí giao dịch. Do vậy nhằm tiết kiệm chi phí giao dịch, các nhà đầu tư sẽ thích những cổ phiếu chi trả tiền mặt hơn. Kết quả nghiên cứu của Banerjee và ctg. (2007) cho thấy chủ sở hữu cổ phần phổ thông có tính thanh khoản thấp hơn thì xác suất nhận được cổ tức tiền mặt sẽ cao hơn và ngược lại.

Nghiên cứu của Ben và Nachi (2006) cũng kiểm tra các yếu tố tác động đến chính sách chi trả cổ tức của các công ty Tunisia. Kết quả chứng minh rõ ràng rằng các công ty Tunisia dựa trên thu nhập hiện tại và cổ tức trong quá khứ để hiệu chỉnh việc chi trả cổ tức của họ. Tuy không xem xét trực tiếp ảnh hưởng của tính thanh khoản của cổ phiếu đến chính sách chi trả cổ tức, tuy nhiên, tác giả có sử dụng biến vòng quay vốn cổ phần trong phương trình hồi quy và kết quả hồi quy cho thấy tính thanh khoản của cổ phiếu có quan hệ ngược chiều với chính sách chi trả cổ tức của DN.

Nghiên cứu của Brockman và ctg. (2008) tìm ra mối quan hệ giữa tính thanh khoản trên thị trường chứng khoán và quyết định mua lại cổ phần của các công ty niêm yết ở Colombia. Nhóm tác giả kiểm tra tác động của tính thanh khoản trên thị trường chứng khoán đến quyết định chi trả cổ tức của các $\mathrm{DN}$. Họ cho rằng tính thanh khoản trên thị trường chứng khoán ảnh hưởng đến chính sách chi trả cổ tức thông qua ảnh hưởng của nó đối với các quyết định mua lại cổ phần. Kết quả nghiên cứu chỉ ra rằng tính thanh khoản của cổ phiếu trên thị trường chứng khoán cao hơn sẽ khuyến khích việc sử dụng chính sách mua lại cổ phần hơn là trả cổ tức tiền mặt. Cũng góp phần trong kho tàng nghiên cứu thực nghiệm về tác động của tính thanh khoản của cổ phiếu đối với chính sách chi trả cổ tức của DN, nghiên cứu của Griffin (2010) cho thấy trong nhiều trường hợp có tồn tại mối quan hệ ngược chiều giữa tính thanh khoản của cổ phiểu và số tiền chi trả cổ tức.

Nghiên cứu khác của Kuo và ctg. (2013) xem xét vai trò của tính thanh khoản và rủi ro, lý thuyết đáp ứng nhu cầu của nhà đầu tư trong việc giải thích hiện tượng tại sao các công ty ở Anh dần không chi trả cổ tức tiền mặt nữa. Khác với các nghiên cứu ở Mỹ, kết quả của họ cho thấy rằng có mối quan hệ giữa chính sách cổ tức và tính thanh khoản của cổ phiếu trên thị trường chứng khoán nhưng mối quan hệ này không được rõ ràng.

Như vậy, hầu hết các nghiên cứu đều cho thấy mối quan hệ ngược chiều của tính thanh khoản của cổ phiếu và chính sách chi trả cổ tức của DN. Tuy nhiên, không ít các nghiên cứu chỉ ra rằng hai yếu tố này hoàn toàn không có mối quan hệ gì với nhau. Điển 
hình như nghiên cứu của Seyedkkhosroshahi, Sabaei và Vatankhah (2013) cho thấy rằng chỉ có các biến đặc tính công ty có ảnh hưởng đến chính sách cổ tức của công ty, trong khi đó các biến nói về tính thanh khoản cổ phiếu không có ý nghĩa thống kê.

Ngoài ra, còn một số nghiên cứu tìm thấy mối quan hệ cùng chiều giữa khả năng thanh khoản và chính sách chi trả cổ tức như nghiên cứu của Michaely và Qian (2017) cho 15 ngân hàng niêm yết trên Sở giao dịch Amman (ASE) trong 7 năm từ 2009-2015. Kết quả nghiên cứu chỉ ra rằng nhu cầu thanh khoản của các nhà đầu tư là một trong những lí do quan trọng để công ty chi trả cổ tức. Tác giả đưa ra bằng chứng thực nghiệm cho thấy một công ty sẽ giảm chi trả cổ tức tiền mặt khi cổ phiếu của công ty có tính thanh khoản cao. Cùng quan điểm với Michaely và Qian (2017), Jiang và ctg. (2017) đã tìm ra hiệu ứng thông tin của tính thanh khoản cổ phiếu có tác động lên chính sách chi trả cổ tức. Cụ thể, tác động thông tin của tính thanh khoản giúp làm giảm bất cân xứng thông tin và vấn đề đại diện trong $\mathrm{DN}$, qua đó khiến cổ đông nội bộ phải chi trả cổ tức nhiều hơn. Kết quả nghiên cứu cho thấy rằng một $\mathrm{DN}$ có tính thanh khoản cao thường có xu hướng chi trả cổ tức nhiều hơn những DN có cổ phiếu thanh khoản thấp.

\section{DŨ LIỄU VÀ PHƯƠNG PHÁP NGHIÊN CÚ̉U}

\subsection{Mô tả dữ liệu}

Mẫu của bài nghiên cứu bao gồm $267 \mathrm{DN}$ phi tài chính được niêm yết trên HOSE trong giai đoạn từ năm 2008-2016. Dữ liệu được thu thập chủ yếu từ Sở Giao dịch chứng khoán TP. Hồ Chí Minh và một số trang Web đáng tin cậy như vietstock.vn, cophieu68, cafef.vn...

\subsection{Mô tả biến}

\subsection{1. Đo lường khả năng thanh khoản}

Dựa vào các nghiên cứu trước đây, có nhiều phương pháp để xác định tính thanh khoản của một cổ phiếu. Tiêu biểu như Amihud (2002) đo lường thanh khoản bằng độ nhay cảm của giá; Lesmond, Ogden, và Trzcinka (1999) đo lường thanh khoản bằng tần suất giao dịch có tỉ suất sinh lợi bằng không; hay Roll (1984) đo lường thanh khoản dựa trên chênh lệch giữa giá hỏi mua và giá chào bán.

Tuy nhiên, đối với các thị trường mới nổi, thước đo dựa vào chênh lệch giá mua và giá bán (bid-ask) thường không có sẵn, do đó các nhà nghiên cứu đã tìm ra các cách khác để đo lường tính thanh khoản của cổ phiếu. Trong đó nổi bật nhất là sử dụng khối lượng giao dịch và coi yếu tố này là đại diện cho tính thanh khoản. Cách xác định tính thanh khoản dựa vào khối lượng giao dịch được gọi là Vòng luân chuyển vốn cổ phần $\left(T U R N_{t}\right)$. Biến này được sử dụng khá phổ biến trong các nghiên cứu của Banerjee và ctg. (2007); Brockman và ctg. (2008); Kuo và ctg. (2013); và Michaely và Qian (2017). Vòng luân chuyển vốn cổ phần được định nghĩa là tỉ số giữa số lượng cổ phiếu đang 
giao dịch và số lượng cổ phiếu đang lưu hành. Tỉ số này thể hiện khía cạnh khối lượng giao dịch trong tính thanh khoản của cổ phiếu tức là nhà đầu tư giao dịch với số lượng cổ phiếu là bao nhiêu. Một cổ phiếu có khối lượng giao dịch nhiều thể hiện các nhà đầu tư có sự quan tâm dành cho cổ phiếu đó, thị trường có sẵn nguồn cung, nguồn cầu để khớp lệnh nhanh chóng các lệnh mua/bán. Do đó tỉ số này càng lớn tức là cổ phiếu được giao dịch một cách thường xuyên hay tính thanh khoản của cổ phiếu cao. Tỉ số này được tính như sau:

$$
T U R N_{i, t}=\frac{\sum_{t=1}^{n} \text { Số luợng cổ phiếu i giao dịch trong ngàyt } t}{n \times \text { số luợng cổ phiếu i đang luu hành }}
$$

Trong đó $n$ là tổng số ngày giao dịch.

\subsection{2. Đo luờng biến chi trả cổ tức}

Các biến thể hiện chính sách chi trả cổ tức của một DN cụ thể như sau:

- $\quad$ DVE (Cash dividends scaled by earnings): Tỷ lệ giữa cổ tức tiền mặt được trả và lợi nhuận sau thuế. Cách đo lường này được đề xuất trong nghiên cứu của Jiang và ctg. (2017). Biến DVE phản ánh DN phân phối lợi nhuận sau thuế như thế nào, dùng để chi trả cổ tức hay giữ lại để tái đầu tư. DVE càng lớn thể hiện DN đang sử dụng hầu hết lợi nhuận để chi trả cổ tức, phản ánh một chính sách chi trả cổ tức tiền mặt cao. Biến này được tính như công thức (2).

$D V E=\frac{\text { Cổ tức tiền mặt đurợc trả }}{\text { Lợi nhuận sau thuế của } D N}$

- $\quad$ DVC (Cash dividends scaled by cash flow): Tỷ lệ giữa cổ tức tiền mặt được trả và dòng tiền thuần từ hoạt động kinh doanh. Cách đo lường này được đề xuất trong nghiên cứu của Jiang và ctg. (2017). Bởi vì dòng tiền thuần từ hoạt động kinh doanh đo lường mức lợi nhuận của $\mathrm{DN}$ tốt hơn lợi nhuận trên báo cáo tài chính vì nhiều $\mathrm{DN}$ có thể có lợi nhuận dương nhưng lại không có khả năng trả nợ. Do đó, chính dòng tiền mới phản ánh hết khả năng trả nợ, thanh toán các nghĩa vụ thuế... Vì vậy, DVC càng lớn càng thể hiện lượng tiền mặt mà $\mathrm{DN}$ dùng để chi trả cổ tức chiếm tỷ lệ lớn từ dòng tiền thuần từ hoạt động kinh doanh, điều này có ảnh hưởng đến khả năng thanh toán của DN. Biến này được xác định theo công thức (3).

$D V C=\frac{\text { Cổ tức tiền mặt đuợc trả }}{\text { Dòng tiền thuần tù hoạt động kinh doanh }}$

- $\quad$ DVP (Cash dividends policy): Biến nhị phân thể hiện khuynh hướng chi trả cổ tức của $\mathrm{DN}$. DVP nhận giá trị 1 khi các $\mathrm{DN}$ có chi trả cổ tức và nhận giá trị 0 nếu $\mathrm{DN}$ không chi trả cổ tức. Biến này được dùng trong nghiên cứu của 
Jiang và ctg. (2017).

\subsection{Mô hình nghiên cứu}

Mục tiêu của bài nghiên cứu này là nhằm xem xét tác động của khả năng thanh khoản của cổ phiếu đến chính sách chi trả cổ tức của $\mathrm{DN}$, dựa theo nghiên cứu Jiang và ctg. (2017), mô hình nghiên cứu được đề xuất như sau:

$$
\text { Payout }_{i, t+1}=\alpha+\beta \times \text { liquidity }_{i, t}+\gamma_{k} \text { Controls }_{i, t}+\varepsilon_{i, t}
$$

Trong đó: Payout là biến phụ thuộc thể hiện chính sách chi trả cổ tức của DN được thể hiện qua các biến DVE, DVC, và DVP; Liquidity: Biến độc lập thể hiện tính thanh khoản của cổ phiếu được đo lường bằng vòng luân chuyển vốn cổ phần (TURN $\mathrm{T}_{\mathrm{it}}$ ); Controls: Các biến kiểm soát gồm các biến đại diện cho các đặc điểm của một $\mathrm{DN}$. Các biến đặc tính trưng cơ bản của một $\mathrm{DN}$ được định nghĩa trong nghiên cứu của Fama và French (2001) bao gồm quy mô (SIZE: được tính theo bằng log (Doanh thu)); Các cơ hội tăng trưởng (Q: Là tỉ số giữa (Giá trị thị trường của cổ phiếu-giá trị sổ sách của tài sản + giá trị sổ sách của nợ)/Giá trị sổ sách của tổng tài sản)); Khả năng sinh lợi (ROE: Tỉ suất sinh lợi trên vốn cồ phần được tính bằng cách lấy lợi nhuận ròng chia cho vốn cổ phần); Lượng tiền mặt mà DN đang nắm giữ (CASH: Tỉ lệ tiền mặt và các khoản tương đương tiền $\mathrm{DN}$ đang nắm giữ so với tổng tài sản của $\mathrm{DN}$ ) và đòn bẩy tài chính (LEV: được tính bằng cách lấy nợ phải trả chia cho vốn cổ phần) và khả năng quản trị của $\mathrm{DN}$ (được đo lường bằng hai biến TOP1 là tỉ lệ \% Cổ phiếu được nắm giữ bởi cổ đông kiểm soát (là những cổ đông lớn hoặc những cổ đông sở hữu từ $5 \%$ cổ phiếu của công ty trở lên ) và biến $\mathrm{DEP}$ : Số lượng thành viên hội đồng quản trị độc lập của $\mathrm{DN}$ ); $i$ và $t$ lần lượt là doanh nghiệp và năm nghiên cứu; và $\gamma_{k}$ là hệ số hồi quy của các biến kiểm soát.

Bởi vì biến phụ thuộc DVE và DVC trong mẫu có các quan sát nhận giá trị 0 do trong năm DN không tiến hành chi trả cổ tức nên ta không cần quan tâm đến tính thanh khoản của cổ phiếu đó như thế nào và tác động ra sao đối với chính sách cổ tức của DN mặc dù vẫn có thông tin về tính thanh khoản của cổ phiếu. Như vậy giá trị của DVE và DVC không có sẵn cho tất cả các quan sát. Trong kinh tế lượng nếu dữ liệu có đặc trưng như vậy thì được gọi là mẫu kiểm duyệt (censored sample). Một mô hình được sử dụng phổ biến trong trường hợp này là Mô hình Tobit, được phát triển đầu tiên bởi Tobin (1958). Trong khi đó biến phụ thuộc thứ hai là DVP là một biến nhị phân, do đó chúng ta sử dụng Mô hình Logistic là phù hợp.

\section{KẾT QUẢ VÀ THẢO LUẬN}

\subsection{Kết quả từ thống kê mô tả}

Từ kết quả thống kê tại Bảng 1 cho thấy các $\mathrm{DN}$ có khuynh hướng chi trả cổ tức cao $(\mathrm{DVP}=82.95 \%)$, trung vị bằng 1 cho thấy hơn $50 \%$ trong tổng số 1255 quan sát có chi trả cổ tức tiền mặt trong năm, vì vậy khuynh hướng chi trả cổ tức tiền mặt của các 
DN cao. Tính trung bình các DN dành khoảng 52.69\% lợi nhuận sau thuế để trả cổ tức (tương ứng tỉ lệ lợi nhuận giữ lại là $47.31 \%$ ) với trung vị là $39.9 \%$, điều này thể hiện hơn $50 \%$ các quan sát trong mẫu dữ liệu sử dụng thấp hơn $52.69 \%$ lợi nhuận để trả cổ tức. Xét về tỉ lệ cổ tức tiền mặt mà cổ đông nhận được so với dòng tiền thuần từ hoạt động kinh doanh cho thấy hầu hết các DN chi trả cổ tức tiền mặt cao hơn so với dòng tiền thuần từ hoạt động kinh doanh, DVC có giá trị trung bình là $135.37 \%$. Tuy nhiên so sánh các quan sát với nhau ta thấy rằng có sự chênh lệch lớn giữa giá trị nhỏ nhất và giá trị lớn nhất, điều này thể hiện chính sách chi trả cổ tức của các DN không nhất quán với nhau.

Tiếp đến, tính thanh khoản của cổ phiếu ở mức trung bình $0.32 \%$, điều này thể hiện chỉ có $0.32 \%$ khối lượng cổ phiếu được giao dịch so với khối lượng cổ phiếu của DN đang lưu hành mỗi ngày. Ngoài ra chênh lệch giữa giá trị nhỏ nhất và giá trị lớn nhất của biến này tương đối cao thể hiện có sự phân hóa cao về khối lượng giao dịch cổ phiếu của các $\mathrm{DN}$ khác nhau, cho thấy nhà đầu tư có sự đánh giá, cân nhắc trong các quyết định lựa chọn cổ phiếu phù hợp với nhu cầu giao dịch của mình, càng chứng tỏ tính thanh khoản của cổ phiếu ngày càng được các nhà đầu tư quan tâm.

Bảng 1. Kết quả thống kê mô tả các biến

\begin{tabular}{lllllll}
\hline Biến & Số quan sát & Trung bình & Độ lệch chuẩn & Trung vị & GTNN & GTLN \\
\hline DVE & 1255 & 0.5269 & 1.0125 & 0.3990 & 0.0000 & 25.7464 \\
DVC & 1255 & 1.3537 & 23.9537 & 0.2548 & 0.0000 & 845.6503 \\
DVP & 1255 & 0.8295 & 0.3762 & 1.0000 & 0.0000 & 1.0000 \\
TURN & 1255 & 0.3235 & 0.6173 & 0.1212 & 0.0000 & 12.5632 \\
ROE & 1255 & 0.1518 & 0.1088 & 0.8454 & 0.0007 & 0.9509 \\
Q & 1255 & 2.0790 & 13.6572 & 1.0116 & 0.1193 & 272.2227 \\
LEV & 1255 & 1.4805 & 2.4946 & 0.4712 & 0.0020 & 0.9437 \\
CASH & 1255 & 0.1118 & 0.1150 & 0.0768 & 0.0000 & 0.9437 \\
SIZE & 1255 & 11.5068 & 2.2212 & 11.8372 & 0.0000 & 13.8672 \\
TOP1 & 1255 & 43.6878 & 26.8556 & 50.1700 & 0.0000 & 99.4600 \\
DEP & 1255 & 3.2478 & 1.1947 & 3.0000 & 0.0000 & 6.0000 \\
\hline
\end{tabular}

Ghi chú: Thông số thống kê trình bày trong bảng này được tính toán dựa trên 1255 quan sát của 267 công ty niêm yết trên HOSE trong giai đoạn từ năm 2008-2016; GTNN: Giá trị nhỏ nhất; và GTLN: Giá trị lớn nhất.

\subsection{Phân tích tác động của khả năng thanh khoản đến chính sách chi trả cổ tức của DN}

Để thấy rõ ảnh hưởng của khả năng thanh khoản đến chính sách chi trả cổ tức của $\mathrm{DN}$, chúng tôi tiến hành chạy sáu mô hình hồi quy như sau: Mô hình (1), (2), và (3) xem xét tác động của khả năng thanh khoản đến chính sách chi trả cổ được đo lường 
bằng các biến DVE, DVC và DVP. Mô hình (4), (5), và (6) thể hiện mối quan hệ giữa khả năng thanh khoản và các biến đại diện cho chính sách chi trả cổ tức khi thêm vào các biến thể hiện khả năng quản trị của DN.

Bảng 2. Ảnh hưởng của khả năng thanh khoản đến chính sách chi trả cổ tức

\begin{tabular}{|c|c|c|c|c|c|c|}
\hline \multirow{2}{*}{ Biến độc lập } & \multicolumn{6}{|c|}{ Biến thể hiện chính sách cổ tức } \\
\hline & DVE (1) & DVC (2) & DVP (3) & DVE (4) & $\operatorname{DVC}(5)$ & DVP (6) \\
\hline \multirow{2}{*}{ TURN } & $-0.1786^{*}$ & $-0.1797 *$ & $-0.7371 *$ & $-0.1785^{*}$ & $-0.1864^{*}$ & $-0.8525 *$ \\
\hline & $(-6.60)$ & $(-7.21)$ & $(-5.46)$ & $(-6.37)$ & $(-7.18)$ & $(-5.82)$ \\
\hline \multirow{2}{*}{ ROE } & $-0.2294 * * *$ & $0.7809 *$ & $0.7801 *$ & $-0.2329 * * *$ & $0.7764 *$ & $0.8085^{*}$ \\
\hline & $(-1.92)$ & $(6.31)$ & $(7.11)$ & $(-1.95)$ & $(6.25)$ & $(7.21)$ \\
\hline \multirow{2}{*}{ Q } & -0.0001 & 0.0012 & 0.0036 & -0.0002 & 0.0011 & 0.0018 \\
\hline & $(-0.52)$ & $(1.41)$ & $(0.23)$ & $(-0.49)$ & $(1.26)$ & $(0.12)$ \\
\hline \multirow{2}{*}{ LEV } & -0.0027 & $-0.0256^{*}$ & 0.0049 & -0.0027 & $-0.0253^{*}$ & $0.0123 *$ \\
\hline & $(-0.42)$ & $(-3.89)$ & $(0.14)$ & $(-0.42)$ & $(-3.84)$ & $(0.36)$ \\
\hline \multirow{2}{*}{ CASH } & $0.3021 *$ & 0.1569 & $3.3764 *$ & $0.3048 *$ & 0.1637 & $3.4000 *$ \\
\hline & $(2.89)$ & $(1.36)$ & $(3.32)$ & $(2.9)$ & (1.42) & (3.34) \\
\hline \multirow{2}{*}{ SIZE } & -0.0004 & -0.0081 & -0.0317 & -0.0004 & -0.0087 & -0.0376 \\
\hline & $(-0.07)$ & $(-1.25)$ & $(-0.8)$ & $(-0.07)$ & $(-1.33)$ & $(-1.96)$ \\
\hline \multirow{2}{*}{ TOP1 } & & & & 0.00002 & -0.0004 & $-0.0073^{*}$ \\
\hline & & & & $(0.04)$ & $(-0.78)$ & $(-2.2)$ \\
\hline \multirow{2}{*}{ DEP } & & & & -0.0055 & -0.0134 & -0.0611 \\
\hline & & & & $(-0.54)$ & $(-1.21)$ & $(-0.92)$ \\
\hline $\mathrm{N}$ & 1255 & 1255 & 1255 & 1255 & 1255 & 1255 \\
\hline Pseudo R2 & 0.0368 & 0.0644 & 0.1247 & 0.0370 & 0.0656 & 0.1300 \\
\hline
\end{tabular}

Ghi chú: Trong ngoặc đơn là thống kê t-statistics; *, **, và *** thể hiện mức ý nghĩa $1 \%, 5 \%$, và $10 \%$.

Kết quả hồi quy trong Bảng 2 cho thấy rằng: Chính sách cổ tức và Tính thanh khoản của cổ phiếu có mối quan hệ ngược chiều nhau và có ý nghĩa thống kê, điều này cho thấy quyết định chi trả cổ tức của một $\mathrm{DN}$ phụ thuộc rất nhiều vào tính thanh khoản của cổ phiếu. Kết quả này giống hầu hết với các nghiên cứu trên thế giới. Lý giải cho kết quả này có thể nói, thị trường chứng khoán Việt Nam đang ngày càng phát triển, ngoài các nhà đầu tư chuyên nghiệp tham gia vào thị trường chứng khoán thì càng ngày sổ lượng các nhà đầu tư nghiệp dư, nhỏ lẻ cũng bắt đầu nhận thức được khả năng sinh lợi mà thị trường này mang lại nên cũng bắt đầu tham gia vào thị trường. Vì chưa có kinh nghiệm và kiến thức về thị trường chứng khoán, cũng như không rõ các kĩ thuật cơ bản để phân tích thị trường, các nhà đầu tư thường đưa các quyết định đầu tư hoặc đầu cơ cổ phiếu chỉ mang tính trực quan về biến động giá hàng ngày cũng như kì vọng của mình để thực hiện các lệnh mua bán. Họ ít quan tâm đến việc nắm giữ cổ phiếu cho đến khi tới ngày chốt danh sách để trả cổ tức. Vì vậy, các DN cũng không quá lo ngại về 
vấn đề chi trả cổ tức, vì đối với họ, giữ lại lợi nhuận để tái đầu tư, thực hiện các dự án để tăng giá trị $\mathrm{DN}$ là một trong những hành động nhằm tối đa hóa lợi ích cho các cổ đông. Do các nhà đầu tư có thể tạo ra dòng tiền để đáp ứng nhu cầu tiền mặt của mình nếu như cổ phiếu mà họ nắm giữ có tính thanh khoản cao mà không quá phụ thuộc vào cổ tức mà DN mang lại từ kết quả hoạt động kinh doanh.

Ngoài ra kết quả hồi quy cũng cho thấy một trong những yếu tố có ảnh hưởng lớn đối với sách chi trả cổ tức của DN có ý nghĩa về mặt thống kê đó là tỷ suất sinh lợi trên vốn cổ phần (ROE), mối quan hệ này thể hiện một $\mathrm{DN}$ có tỷ suất sinh lợi trên vốn cổ phần càng lớn thường thực hiện chính sách chi trả cổ tức tiền mặt cao. Kết quả này tương tự với các nghiên cứu thực nghiệm trước đây. Bởi lẽ, một $\mathrm{DN}$ có tỷ suất sinh lợi càng lớn càng thể hiện khả năng sử dụng và khai thác hiệu quả nguồn lực của mình trong quá trình hoạt động kinh doanh, vì vậy có thể tin tưởng vào dòng thu nhập tương lai của $\mathrm{DN}$. Cũng vì thế mà uy tín của $\mathrm{DN}$ trên thị trường được nâng cao, có thể dễ dàng tiếp cận các nguồn vốn vay một cách dễ dàng hơn, từ đó $\mathrm{DN}$ có thể thực hiện chính sách chi trả cổ tức tiền mặt cao.

Đòn bẩy tài chính LEV có tác động nghịch biến và có ý nghĩa thống kê với chính sách chi trả cổ tức. Theo lý thuyết của Fama và French (2001) cũng như các nghiên cứu thực nghiệm của nhiều tác giả ở nhiều thị trường trên thế giới, thì một DN sử dụng càng nhiều nợ vay thì lợi nhuận sẽ được ưu tiên trả cho các chủ nợ trước khi thanh toán cổ tức cho các cổ đông. Do đó, sử dụng nợ vay càng nhiều, thu nhập để trả cổ tức càng thấp bởi những điều khoản hạn chế nhằm bảo vệ quyền lợi của các chủ nợ. Vì vậy, DN có đòn bẩy tài chính càng lớn sẽ tiến hành chi trả cổ tức với tỉ lệ cổ tức trên lợi nhuận và tỉ lệ cổ tức trên dòng tiền từ hoạt động kinh doanh thấp, một phần vừa giúp các cổ đông cảm thấy hài lòng, một phần vẫn có thể giải quyết các nhu cầu trả nợ của DN.

Xét đến mối quan hệ giữa lượng tiền mặt mà $\mathrm{DN}$ đang nắm giữ và chính sách chi trả cổ tức của $\mathrm{DN}$, kết quả hồi quy cho thấy một $\mathrm{DN}$ nắm giữ lượng tiền mặt dồi dào thường chi trả cổ tức cao. Kết quả này tương tự với các nghiên cứu của Fama và French (2001) và Jiang và ctg. (2017). Bởi lẽ, trừ khi $\mathrm{DN}$ có lịch sử với lượng tiền mặt biến động thất thường, không ổn định, cần thiết phải giữ lại một lượng tiền mặt lớn để đáp ứng các nhu cầu khẩn cấp, thì một $\mathrm{DN}$ thường sẽ không nắm giữ một lượng tiền mặt cao, vì điều này đồng nghĩa với việc tiền mặt tạm thời nhàn rỗi hoặc không có các cơ hội đầu tư. Mặt khác xét đến vấn đề đại diện, khi lượng tiền mặt dồi dào cho phép các nhà quản trị công ty có thể đánh giá các dự án sơ sài và sẵn sàng thực hiện các cơ hội đầu tư một cách hời hợt, điều này gây ảnh hưởng đến giá trị công ty. Bên cạnh đó, lượng tiền mặt dồi dào cũng là nguyên nhân dễ khiến các nhà quản trị thực hiện các hành động trục lợi cho bản thân mình.

Biến số lượng thành viên hội đồng quản trị độc lập có mối quan hệ ngược chiều với chính sách chi trả cổ tức của DN. Để giải thích cho kết quả này, ta thấy tại Việt Nam, số lượng các $\mathrm{DN}$ đủ điều kiện niêm yết trên sở giao dịch chứng khoán ngày càng 
nhiều, tuy nhiên hầu hết là các DN với quy mô vừa và nhỏ, khả năng tiếp cận thị trường vốn và huy động vốn nhờ phát hành cổ phiếu cổ phiếu mới còn yếu, do đó phần lớn cổ phiếu được nắm giữ bởi các cổ đông thành lập công ty. Vì vậy các cổ đông kì vọng sự tăng trưởng của $\mathrm{DN}$ hơn là cổ tức nhận được. Do đó, tỉ lệ cổ phần được nắm bởi các cổ đông kiểm soát càng cao thì $\mathrm{DN}$ chi trả cổ tức cổ tức tiền mặt càng thấp. Mặt khác, xét về vấn đề đại diện, một $\mathrm{DN}$ có số lượng thành viên hội đồng quản trị độc lập càng nhiều càng gia tăng vấn đề chi phí đại diện cho $\mathrm{DN}$. Bởi lẽ, nguồn thu nhập của các thành viên hội đồng quản trị độc lập không bị ảnh hưởng bởi chính sách chi trả cổ tức của DN. Đối với các thành viên hội đồng quản trị độc lập, họ thích một tỉ lệ chi trả cổ tức thấp và giữ lại lợi nhuận cao để nếu có các cơ hội đầu tư hấp dẫn DN có sẵn nguồn lực để thực hiện các cơ hội đầu tư đó. Vì vậy, một $\mathrm{DN}$ có số lượng thành viên hội đồng quản trị độc lập càng nhiều thì $\mathrm{DN}$ thực hiện chính sách chi trả cổ tức càng thấp.

\section{KẾT LUẬN VÀ HÀM Ý CHÍNH SÁCH}

Mục tiêu của bài nghiên cứu này là tìm kiếm mối liên hệ giữa tính thanh khoản của cổ phiếu và chính sách chi trả cổ tức của DN. Kết quả phân tích mẫu quan sát gồm 267 DN niêm yết trên HOSE cho thấy cổ phiếu của doanh nghiệp có tính thanh khoản càng cao (tức là có thể dễ dàng giao dịch để chuyển đổi sang tiền mặt trên thị trường chứng khoán nhằm đáp ứng các nhu cầu của các nhà đầu tư) thì xác suất doanh nghiệp đó dùng tiền mặt để chi trả cổ tức càng thấp. Ngoài ra kết quả cũng thể hiện khi mà thị trường chứng khoán ngày càng phát triển thì tính thanh khoản của cổ phiểu ngày càng có xu hướng tác động đến chính sách chi trả cổ tức của DN thay thế các biến thể hiện các đặc trưng của $\mathrm{DN}$ như quy mô $\mathrm{DN}$, khả năng tăng trưởng hay tỉ lệ cổ phiếu được nắm giữ bởi cổ đông kiểm soát.

Từ kết quả nghiên cứu trên, chúng tôi thấy rằng khi hoạt động của thị trường chứng khoán diễn ra sôi động, các nhà đầu tư sẽ quan tâm nhiều hơn đến tính thanh khoản của cổ phiếu và họ có thể tự tạo ra thu nhập cho mình nếu như cổ phiếu đó có tính thanh khoản cao. Do đó, các DN có thể áp dụng một chính sách chi trả cổ tức tiền mặt thấp để tận dụng nguồn lực cho các cơ hội đầu tư, từ đó nâng cao giá trị DN, uy tín cũng như niềm tin trong mắt các nhà đầu tư, góp phần gia tăng tính thanh khoản của cổ phiểu. Vì vậy, cổ tức tiền mặt nhận được với tính thanh khoản của cổ phiếu có thể thay thế nhau để làm hài lòng nhu cầu của các nhà đầu tư. Thêm vào đó, về ý nghĩa của hệ số hồi quy, tính thanh khoản có hệ số hồi quy cao đã thể hiện tác động rõ ràng của nó đối với chính sách chi trả cổ tức thay vì các yếu tố thể hiện các đặc trưng của DN như các giai đoạn trước đây.

\section{TÀI LIỆU THAM KHẢO}

Amihud, Y. (2002). Illiquidity and stock returns: Cross-section and time-series effects. Journal of Financial Markets, 5(1), 31-56.

Banerjee, S., Gatchev, V. A., \& Spindt, P. A. (2007). Stock market liquidity and firm 
dividend policy. Journal of Financial and Quantitative Analysis, 42(2), 369-397.

Ben, N. S., \& Nachi, W. (2006). Does the Tunisian accounting reform improve the value relevance of financial information? Retrieved from https://papers.ssrn.com/ sol3/papers.cfm?abstract_id=888922.

Brockman, P., Khurana, I. K., \& Martin, X. (2008). Voluntary disclosures around share repurchases. Journal of Financial Economics, 89(1), 175-191.

Fama, E. F., \& French, K. R. (2001). Disappearing dividends: Changing firm characteristics or lower propensity to pay? Journal of Financial Economics, 60(1), $3-43$.

Jiang, F., Ma, Y., \& Shi, B. (2017). Stock liquidity and dividend payouts. Journal of Corporate Finance, 42, 295-314.

Kuo, J. M., Philip, D., \& Zhang, Q. (2013). What drives the disappearing dividends phenomenon? Journal of Banking \& Finance, 37(9), 3499-3514.

Griffin, C. H. (2010). Liquidity and dividend policy: International evidence. International Business Research, 3(3), 3-9.

Hoda, T., \& Uno, J. (2011). Liquidity, ownership structure, and market share repurchases: Evidence from Japan. Retrieved from https://papers.ssrn.com/sol3/ papers.cfm?abstract_id $=1914152$

Lesmond, D. A., Ogden, J. P., \& Trzcinka, C. A. (1999). A new estimate of transaction costs. The Review of Financial Studies, 12(5), 1113-1141.

Miller, M. H., \& Modigliani, F. (1961). Dividend policy, growth, and the valuation of shares. The Journal of Business, 34(4), 411-433.

Michaely, R., \& Qian, M. (2016). Stock liquidity and dividend policy: Evidence from a natural experiment. Retrieved from https://editorialexpress.com/cgi-bin/ conference/download.cgi?db_name=CICF2017\&paper_id=202

Roll, R. (1984). A simple implicit measure of the effective bid-ask spread in an efficient market. The Journal of Finance, 39(4), 1127-1139.

Seyedkkhosroshahi, S., Sabaei, A., \& Vatankhah, P. (2013). Stock market liquidity, firm characteristics and dividend payouts. Journal of American Science, 9(4s), 172-177.

Tobin, J. (1958). Estimation of relationships for limited dependent variables. Econometrica: Journal of the Econometric Society, 26(1), 24-36. 